\title{
YOUTH IN SOCIETY
}

\author{
Paul J. Galea, \\ Youth Service Organiser, \\ Ministry of Education and Culture
}

\section{Change and society}

We live today in an era when forces which were released by man at the beginning of the industrial revolution seem to have assumed an impetus of their own, which drives us all at an everincreasing speed to further "happiness and prosperity".

The whole aspect of adolescence is embedded within the overall structure of our modern society. This suggests that whatever may be done or provided for adolescents must stem from the overall concept of society. If society is confused, violent or destructive then the confusion, violence and destructiveness of young people can be allayed only in the concept of an approach to that society as a whole.

Youth finds itself confronted with the challenging situation and is in most cases "unguided", voicing an uncertain response when it does not prefer to escape the encounter of change and tradition. This change brings with it the promise of a new freedom from need, disease, ignorance and superstition. It offers to man a hope of dignity and equality and of the abolition of barriers which for ages have separated man from man.

Social change began to accelerate when economic development created higher living standards. Economic development is the conscious process by which political and economic forces bring about industrialisation and the transformation of an old and static economy to a dynamic and stable state able to secure high living standards.

Malta is a country of rapid social change. Malta is also engaged in a struggle for economic development. It is a country where traditions and cultural values live and has also a historical heritage which has left its roots in national institutions.

Young people in Malta are not different from their counterparts in other countries. Various factors have 
contributed to this. The mass media of communication provide them with the information they need and advertising presents new customs, styles and products which are similar to those of young people elsewhere. These new influences have contributed to making Maltese youth conscious of what is happening around, and so more aware of the problems of society in general. Adolescence is a period of life when reaction to a particular situation is likely to be emotional. This response is exaggerated by the fluidity of society in the social, political, individual and ideological senses. Young people in Malta are conscious of a world divided into two power complexes with the means ready for its total destruction.

Our youngsters have developed values and attitudes of their own. Environment has a lot of influence, but these attitudes are not always in harmony with those of the adult generation. One result of this is a clash of values, and consequent conflict and frustration. If the adolescents are to fit into the general pattern then they must play the roles proposed to them; but if in fact they do not fit in, then it may be that Malta itself must change. "Malta will have to change in a way that a place be found in it for adolescents". This was stated in a Report published by the Cana Movement in 1961. Since then Malta has changed. Society cannot ignore the contribution that young people have to make in shaping the future and it must be ready to listen to them and ready to give way.

The gulf between the generations was also mentioned in a Report published by the Youth Service Commission in 1964. The Report referred to the anxiety that such a situation creates among the generations and the imperative necessity for remedial measures before the estrangement becomes permanently established.

The forces of change aim at the achievement of economic development. This should encourage the younger generation to achieve high aims and look forward to change. Young people are entrusted with a challenging task for their country. As an awareness of their own potentialities increases youth begin to play an ever increasing role in bringing about change. This can be achieved in leadership positions and through bringing pressure of all forms to bear on existing institutions.

Youth is motivated by ideals such as social justics, freedom, peace, dignity and is becoming an agent for honesty and efficiency in the conduct of public affairs. 
The entire Maltese youth population is not engaged in this function, but we have recently witnessed a revival among the younger generations who have begun to see this role and to perform it and to find a new pride and self respect in the process. This is evident in the fact that recently we have seen the birth of new organisations, less rigid in their outlook and whose work is based on experimentation.

Maltese youths are conscious of the need for a deep human relationship. Attitudes towards social relationship provide insight into present day youth problems. These attitudes can be described as the need for social contacts and the desire to be useful to others together with an affirmation of optimism and confidence in the future and a certain degree of realism.

New social relations are in the process of creating a generation the nature of which has never existed. The younger generation is faced with the decline of values which has been the source of identity in the past.

In the present pluralistic society the family, the school, work and leisure play an important role. A young person is at present experiencing many impluses which do not seem to belong together. An orientation based on valued and accepted behaviour patterns is almost impossible for in such a fluid society it may not help youth to find their way; on the contrary it may make them insecure.

Change and the family

The still prevailing family loyalties result in some young people bearing the burden of responsibility towards the family.

The family has always been a stable point of orientation. It is here that the young have been prepared for adulthood. But because of the many changes in society the function of the family has also changed. The new task of the family is to provide a place of education to help the young person to become a private personality in modern society. The family in Malta is still strong. The family has sustained the strains and stress of the external world. Affection and understanding are the key words to family life.

Parents occupy a special position in relation to young people. The changing conditions of society have created conditions which are as new to parents as they are to their children. This has produced less security among parents. 
Vastly increased opportunities in the educational field, and the availability of the mass media have opened horizons which never existed in the past. Young people have had better chances than their parents and hence this may be partly responsible for the "battle between the generations".

Another situation worth noticing is that since many young people today earn more than their fathers, parents have to rely on the earnings of the children.

It is worth mentioning here that young people still feel that they owe allegience to the family, but sometimes the family is making demands on them which they cannot accept. The family is limiting their freedom, and their mobility, and hence young people feel insecure. In a way the family instead of helping young people to develop is sometimes creating barriers which young people object to very strongly.

\section{Changes relating to women and girls}

This has produced a different mentality in young girls which is not in line with that of the parents and the adult generation. It is obvious that the se new ideals have brought with them a certain amount of apprehension on the part of the adult generation, although it may be argued that this results essentially from the sense of insecurity of the adult generation.

Another aspect of great importance are the new opportunities and responsibilities of young women. These have undergone a radical change with implications on their life. An example of this is the exodus of the female from the home in order to find work in industry.

Sex and morality

An atmosphere of sexual stimulation surrounds young people everywhere. Sex education has been neglected in the past. Change has brought with it a new pattern of relationship between the sexes together with more sexual freedom. This change involves also a breakaway from deep-rooted attitudes to marriage which were the pillars of the past.

A society which comes in contact with contrasting cultures will have to undergo some re-thinking about its values. Morality of young people has changed considerably and Malta has not been spared from this influence. Religious influence has diminished and moral values are no longer. 
The role of the Church

The Church which has again and again led the entire nation has now a great and unique role to play in respect of the younger generation. Our young people are influenced by religion because religion is present in the home, in the streets, at school, at work, and almost everywhere. Some young people tend to conform but others question religious beliefs. Young people start asking questions and it is here that they need a realistic approach. Vatican II has done a lot towards a realistic approach, but some youths still follow the traditional religious belief, either because they cannot run away from it or because of family pressures. Young people want to be different and be freer in their thinking and way of behaviour. The clergy play an important role.

The church may be even surprised at the positiveness of the response which youth will provide to their invitation to constructive particupation in religious life. Young people do not want to be preached at, they are ready to discuss but want to be allowed to express views freely and openly. A church that dictates to young people is closing its doors on the young generation. The church must therefore learn to think about youth as an important element in their role as part of "people of God" and give them full encouragement and freedom to experiment in overcoming their difficulties. This process may be difficult and young people may make mistakes but a realistic church must be prepared for this.

The use of leisure

A basic question for young people is how to spend their leisure time. The responsible use of leisure time and the provision of the facilities for it is the responsibility of society.

There is today an increasing awareness that a responsible use of leisure time is essential for the development of the personality.

During leisure it is probable that adolescents find themselves more exposed to the values shared by the contemporary Western World. These values are not always shared by the other members of the family. Adolescents are conscious of the contradictions that exist in our society. 
Youth in a consumer society

Young people today are faced with a challenge. Our socalled consumer society pretends to be interested in the young. Young people today have at their disposal a purchasing power which is expanding all the time. They represent the prey of the commercial enterprise. The advertising trade appeals to young people and exploits youth.

Adults may feel out of touch with all this "young" music, "young" clothes, "young" hairstyles, "young" drinks. But young people today are living in a world that the adult generation has handed over to them. There is also an indication that young people are living in a world of their own and the adult generation in another.

Styles of dress, dance, and behaviour are ways in which the young person demonstrates that he belongs to a particular group and serve as a means of identification. We are in fact witnessing the creation of new needs by those who control the means of production and it is evident that those who hold the reins of production also govern the conditions of consumption.

Youth and society

Society becomes the target of this challenge. In Malta we have not witnessed yet a large scale uprising of young people as was the case in other countries, but it is evident that there is uneasiness among our young people. This uneasiness has its roots in the social and economic problems of the country. Our youngsters have clearly shown their intent on opening wider horizons.

It seems to be essential to restore the se young people's confidence in the possibilities of effective action. Youngsters are not lacking in criticism nor in enthusiasm, which are indispensable for any cause of action. Unfortunately the people in authority disregard the young. Maltese youth have been denied their share in the responsibility for the leadership of the nation at all levels. Some of our youth movements are in the hands of the older generation. This frustrates ambition and encourages subservient attitudes to the adult generation.

Many discussions on adolescence concentrate upon the state of mind of the adolescent, but we have also to consider how society looks on adolescence. Adults have gradually come to believe that young people are distinct from the rest of the adult 
world, they have also institutionalised their expectations. They have also adopted a defensive approach, but adolescence will best be served if adults gives it recognition and acceptance. Society will equip its young to participate in and to benefit from society itself. What we need is a society aware of the needs of the young and understanding enough to guide them in the relationships which are required, thus providing for those relationships within its own situations. The function of society is not protection but open mindedness, approachability, flexibility and social maternity.

To conclude, allow me to quote from the Report "Youth in Malta" published in 1964:

"The realisation is steadily growing that much essential work remains to be done in this field. Misunderstanding of the pre-adult by the adult is as much responsible for lack of communication as that of the adult by the pre-adult with less excuse".

Meeting the needs of youth

The "Service of Youth" (and by Service of Youth I mean a partnership between all the forces working together for the social education of our adolescents), should question its role and function. Unfortunately very little research has been undertaken on the real needs of young people in Malta. Modern methods of research should be used in order to make a full sociological study of the present needs of society as a whole. The present available reports are very useful but a more detailed analysis is needed. Too often we have to rely on assumptions reached by experts in other countries.

More experimentation is needed by one and all in order to serve better our younger generation.

The Service of Youth should offer young people wider horizons and help young people solve their problems in a practical way. This can only be achieved if our young people were given better chances for future development.

Voluntary bodies will have to re-examine their techniques and adapt modern ones. Genuine interest in youth is needed and the mass media can be a great help in this field.

Youth movements must understand that they exist for the needs of young people not for their own needs. Young people want dialogue and they welcome those organisations that offer scope 
for an involvement. Youth movements should be aware that they serve better the needs of youth if they involve youth more in decision making and offer them opportunities to feel that they are effectively participating in the life of their community. They should look again at their interpretation of "loyalty", for it may be that in their eagerness to involve members they have demanded a loyalty which restricts development of the individual.

Through involvement and observation society has to understand the ways in which it pursues its aims and to what degree it has fulfilled them.

We need a Service of Youth that would aim at helping to break down the barriers between young people and adults, that would bring together formal and informa education, prepare young people to take an active part in society, and offer services as an integral part of the community.

The Report on "Youth in Malta" said:

"The major requisite seems to be closer co-operation and co-ordination between all those operating in the field. In this way a much more effective use might be made of the resources already available on a much more developed scale".

Increased training facilities should be provided for young people and youth workers and special attention should be given to the needs of young people who have left school. Industry and commerce must be vitally concerned with a purposeful use of leisure. Adult associations should offer more active help to youth in general.

Lastly an effective policy for youth, by youth and with youth would help in the establishment of an effective Service of Youth.

Young people need acceptance, they want to be identified, to feel they matter, and it is the job of society to help them understand what is involved in decision making.

Youth work should be seen within the context of social education, and should be concerned with relationships between the generations and between young people and their community, and as a response to the social, educational and personal need of the young in relation to society. Only in this way can the Service of Youth be effective. 